\title{
Intraspecific trait variability of trees is related to canopy species richness in European forests
}

Raquel Benavides ${ }^{\mathrm{a}, \mathrm{b}}$, Fernando Valladares ${ }^{\mathrm{b}, \mathrm{c}}$, Christian Wirth ${ }^{\mathrm{d}, \mathrm{e}}$, Sandra Müller ${ }^{\mathrm{a}}$, Michael Scherer-Lorenzen ${ }^{\mathrm{a}}$

${ }^{a}$ Geobotany, Faculty of Biology, University of Freiburg, 79104 Freiburg, Germany; ${ }^{b}$ Department of Biogeography and Global Change, Museo Nacional de Ciencias Naturales, Consejo Superior de Investigaciones Científicas, 28006 Madrid, Spain; ${ }^{\text {Biodiversity and }}$ Conservation Area, Universidad Rey Juan Carlos, 28933 Móstoles, Madrid, Spain; ${ }^{\mathrm{d}}$ Systematic Botany and Functional Biodiversity Study Group, University of Leipzig, 04103 Leipzig, Germany; ${ }^{\mathrm{C}}$ German Centre for Integrative Biodiversity Research (iDiv) Halle-JenaLeipzig, 04103 Leipzig, Germany.

${ }^{1}$ Correspondence: Raquel Benavides.

Present address: Museo Nacional de Ciencias Naturales, (MNCN-CSIC), C/Serrano 115 dpdo. 28006, Madrid, Spain. Tel: +34 917452500 ext. 980803 ; Fax: +34 9156408 00. Email: rbenavidescalvo@gmail.com 


\section{ABSTRACT}

Functional diversity informs about biodiversity-ecosystem functioning relationships. The intraspecific component of functional diversity (i.e. the phenotypic space of each species) depicts individual differences in the resource use and fitness among conspecifics, and gives valuable information about the functional similarity (competition) or dissimilarity (complementarity) of coexisting species. Here, we quantified trait differences within tree species along local diversity gradients to shed light on the role that this intraspecific variability exerts on functional complementarity of tree species. We measured architectural traits in 5,036 individuals and leaf traits in 1,403 individuals from nine dominant tree species, surveyed in 92 plots located in three major European forest types (Mediterranean, temperate and boreal forests). In each forest type, plots were positioned along a canopy richness gradient, with every study species present in different species richness levels, including monocultures. Our results showed that the relative magnitude of intraspecific trait variability to community-level variability is high in these forests. At the species level, we found adjustments of species leaf traits (mean shifts) in response to neighbouring trees, suggesting the existence of processes that limit niche overlap. We also found higher variability in architectural traits of conspecific individuals in more diverse canopies, suggesting greater niche packing and a more efficient use of available space as the number of species in the canopy increases. Altogether, our results support the hypothesis that differential responses of individuals within a species promote species complementarity, suggesting that biodiversity-ecosystem functioning relationships cannot be properly estimated without accounting for the intraspecific level of functional variation.

\footnotetext{
Abbreviations. ITV: Intraspecific Trait Variability; ETV: intErspecific Trait Variability; H: tree height; CP: crown projection area; SR: species richness
} 
Keywords: biodiversity; complementarity; European forest; FunDivEUROPE; intraspecific variability; plant functional traits.

\section{INTRODUCTION}

An increasing body of work shows the positive effect that plant diversity exerts on different ecosystem functions and services, accounted either individually (e.g. productivity, stability or resilience against pests or pathogen outbreaks) (Allan et al., 2013; Balvanera et al., 2006; Cardinale et al., 2012) or together (the so-called 'multifunctionality') (Gamfeldt et al., 2008; Lefcheck et al., 2015; van der Plas et al., 2016). For individual ecosystem functions, two additive mechanisms have been identified supporting this positive relationship: niche complementarity and selection effects (Loreau and Hector, 2001; Turnbull et al., 2013). The former assumes that diverse communities comprise species with different resource use (i.e. differences in resource requirements or spatial/temporal distribution); the latter assumes that competition leads high-yielding species to dominate in mixtures.

Including functional diversity, in addition to the number of species, gives further information about the biodiversity effect on ecosystem functioning as it can better capture species interactions in a community (Cadotte, 2017; Cadotte et al., 2011; Ebeling et al., 2014). Traits determine how individuals use resources from their environment (McGill et al., 2006), and provide information about species niche and fitness differences (Kraft et al., 2015). Species trait differences are therefore directly linked to the complementarity and competitive ability of coexisting species (Carroll et al., 2011; Loreau et al., 2012), key components of biodiversity that influence how an ecosystem operates or functions (Tilman 2001). Since approximately $25 \%$ of total estimated trait variation in plant communities worldwide is found within species (Albert et al., 2010a, b; Siefert et al., 2015), intraspecific 
variability should not be ignored when quantifying biodiversity effects on ecosystem functioning (Aschehoug and Callaway, 2014; Ashton et al., 2010; Zhu et al., 2015). Accordingly, an increasing number of studies is revealing the importance of intraspecific variability for different ecological questions, including functioning of plant communities (Crutsinger et al., 2006; Lecert and Chauvet, 2008), community assembly (Jung, et al., 2010; Siefert 2012), species distribution forecasting (Cochrane et al., 2015; Valladares et al., 2014), and mechanisms ruling species interactions and coexistence (Lichstein et al., 2007; Roscher et al., 2015).

Traits are measured at the individual level, and the distribution of trait values within a species identifies its functional trait space. Hence, considering trait variability between and within species entails that the functional space can be occupied continuously by all the individuals making up the community. Approaches based on species mean traits underestimate species interactions (by ignoring functional overlaps) and the utilisation of available resources (de Bello et al., 2013; Violle et al., 2012). The functional overlap among coexisting species reveals their similarity, i.e. the functional space they share (Violle et al., 2012). Thus, low trait overlaps in rich communities would support that species exploit different niches and are thus complementary in their resource use. Meanwhile, large overlaps would imply functional redundancy among coexisting species. Despite the large effort required to quantify and collate trait variation within species, several studies have tackled the relationship between species richness and trait distributions and overlaps in order to elucidate mechanisms that underpin the structure of natural communities (Bastias et al., 2017; Kumordzi et al., 2015; Le Bagousse-Pinguet et al., 2014). However, results are contrasting and there is no clear evidence of similar species-specific responses (trait adjustments) to changes in species richness and composition. Insights from biodiversity experiments (carried out primarily with herbaceous species) have revealed a potential role 
of intraspecific variability for fostering species complementarity (Ashton et al., 2010; Mitchell and Bakker, 2016; Zuppinger-Dingley et al., 2014; Zhu et al., 2015). For instance, Zhu et al., (2015) assessed that $64 \%$ of the total net biodiversity effect measured on light capture compared to monocultures in wheat and maize intercrops was due to species plasticity.

Here, we have quantified trait variation within tree species along diversity gradients of canopy trees in mature, European forests to address whether intraspecific trait variability enhances species complementarity. We have compared the intraspecific trait variability (hereafter ITV) of trees growing in pure vs. mixed stands in three contrasting forest types: a continental-Mediterranean, a mountainous mixed temperate and a boreal forest. First, we have evaluated the magnitude of ITV at the community level relative to the variability among species (intErspecific Trait Variation, hereafter ETV) across the forest types, and analysed its relationship with species richness of the canopy tree layer. We further analysed how this component of the variability at the community level varies with species richness.

Subsequently, we analysed the relationship between species richness and ITV at the species level, i.e. trait mean and variance among conspecific individuals, searching for species-specific responses to the diversity gradient. Given the contrasting results found in previous studies of how species richness affects ITV (Bastias et al., 2017; Kumordzi et al., 2015; Le Bagousse-Pinguet et al., 2014; Siefert et al., 2015), we posit three alternative hypotheses for this relationship (Fig. 1): i) species richness and ITV are not correlated, suggesting either full complementarity among species or non-saturated communities; ii) species richness and ITV are negatively correlated, implying a reduced ITV due to resource partitioning and avoidance of niche overlap with increasing species richness (McGill et al 2006; Tilman, 1982); iii) species richness and ITV are positively correlated, entailing higher temporal or spatial heterogeneity in the community that provides new opportunities (new 
niche availability) and wanes competition among individuals (Stein et al., 2014). This positive correlation might arise either by an increment of intraspecific trait variability at the community level (changes in trait variance among conspecifics in two different communities), or by trait mean shift of a species.

\section{Monocultures $\quad$ Mixed stands}

1)

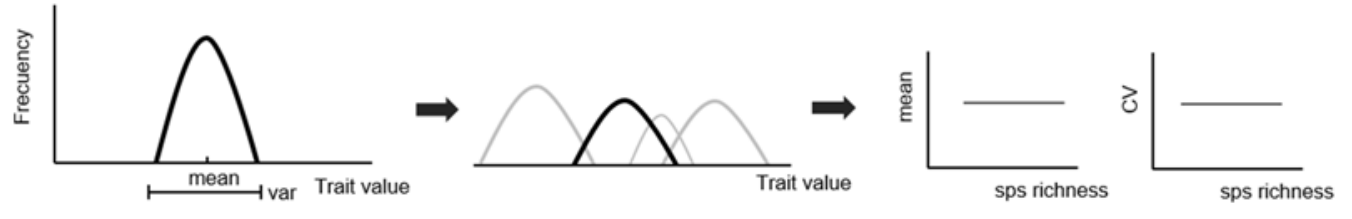

2)

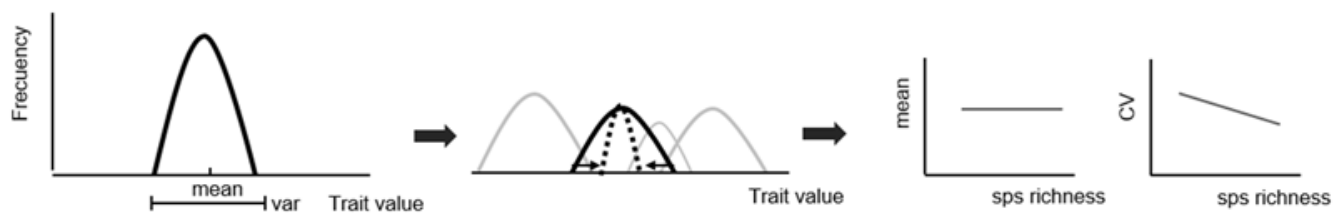

3)
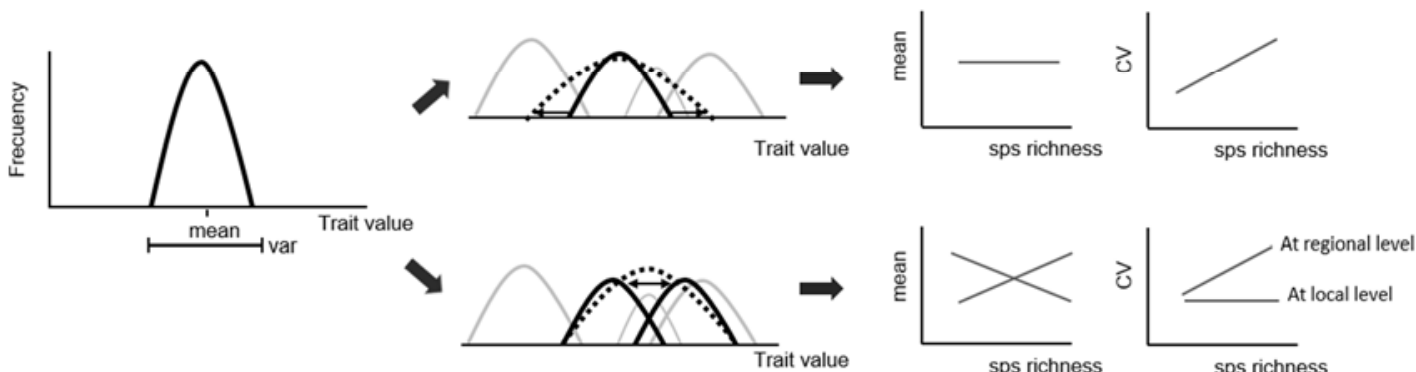

Fig. 1. Alternative hypotheses for the relationship between intraspecific trait variability (ITV) and species richness (SR) in a forest community. The comparison of a species trait distribution between conspecific (monocultures) vs. heterospecific neighbours (mixed stands) is addressed in terms of mean trait value and trait variance (assessed as coefficient of variation -CV-). 1) Null relationship, ITV does not correlate with species richness (neither its mean value nor the variance); 2) ITV decreases with species richness, i.e. variance diminishes around the optimal value; or 3) ITV increases with species richness either by local variance increment or by trait mean shift and the ensuing increment of the overall phenotypic space at a larger scale. 


\section{METHODS}

\section{Study sites}

The three study sites belong to a network of plots established for the European project FunDivEUROPE (Functional significance of forest biodiversity; www.fundiveurope.eu), which comprise some of the major European forest types (Baeten et al., 2013). In particular, this study was located in a continental-Mediterranean mixed forest in the Alto Tajo Natural Park (Spain), a mountainous beech forest in Râşca (Carpathian Mountains, Romania) and a boreal forest in North Karelia (Finland). Hereafter, we refer to them as 'Mediterranean', 'temperate' and 'boreal', respectively (Table 1).

In each site, plots $(30 \times 30 \mathrm{~m})$ were established following a diversity gradient of regional dominant tree species in different combinations (replicated at least twice), ranging the species richness (SR) of the canopy from 1 to 3 in Finland, and from 1 to 4 in Romania and Spain. Every dominant species was present in all species richness levels (see in Appendix A, Table A.1 the detailed species combination design). The total number of sampled plots were 92 and the tree species were Pinus nigra Arnold, Pinus sylvestris L., Quercus faginea Lam. and Quercus ilex L. in the Mediterranean forest with 36 plots in total; Abies alba Mill., Acer pseudoplatanus L., Fagus sylvatica L. and Picea abies [L.] Karst. in the temperate forest; and Betula pendula Roth., Picea abies [L.] Karst. and Pinus sylvestris L. in the boreal forest, both with 28 plots. Criteria for plot selection are explained in detail in Baeten et al., (2013) and relied on two main principles: 1) mixed plots had high evenness, i.e. species had similar relative abundances; 2) variation of environmental conditions among plots within a region (e.g. soil, topography) was minimised, reducing the covariation between environmental gradients and species richness. 
Table 1. Brief description of the study sites, species and environmental conditions.

$\begin{array}{cc}\text { North Karelia, } & \text { Carpathian mountains } \\ \text { Finland } & \text { Romania } \\ \text { (boreal) } & \text { (temperate) }\end{array}$

\begin{tabular}{lccc}
\hline Coordinates & $62.4^{\circ} \mathrm{N}-29.4^{\circ} \mathrm{E}$ & $47.3^{\circ} \mathrm{N}-25.5^{\circ} \mathrm{E}$ & $40.7^{\circ} \mathrm{N}-1.9^{\circ} \mathrm{W}$ \\
& Betula pendula & Abies alba & Pinus nigra \\
Dominant species & Picea abies & Acer pseudoplatanus & Pinus sylvestris \\
& Pinus sylvestris & Fagus sylvatica & Quercus faginea \\
Annual mean $\mathrm{T}\left({ }^{\circ} \mathrm{C}\right)^{*}$ & $2.1(0.3)$ & $5.5(0.5)$ & $9.7(0.6)$ \\
Annual mean P $(\mathrm{mm})^{*}$ & $631.8(5.9)$ & $691.1(24.9)$ & $537.4(27.3)$ \\
Elevation range (m) & $87-233$ & $655-1062$ & $960-1404$ \\
Soils & Podzols and glacial tills, & Tertiary sandstone and \\
clay, loamy sediments & Calcareous, reddish Terra rossa \\
Main forest types (EEA-code)* & Boreal & Carpathian mountainous & Coniferous and broadleaf \\
Species richness gradient & $1-3$ & beech forest & Mediterranean forests \\
Number of plots & 28 & $1-4$ & $1-4$ \\
Plots per richness level & $11 / 14 / 3$ & 28 & 36 \\
\hline
\end{tabular}

* $\mathrm{T}=$ temperature, $\mathrm{P}=$ precipitation, figures in brackets are the standard deviations; EEA: European Environmental Agency (source: EEA Technical Report No 9/2006; https://eea.europa.eu).

\section{Study traits, sampling and measuring}

We considered traits at the leaf and at the whole-plant levels. At the leaf level, we chose two morphological leaf traits associated with resource acquisition-conservation tradeoff (Wright et al., 2004), namely specific leaf area (SLA, the area of an individual fresh leaf divided by its dry mass) and leaf dry matter content (LDMC, the oven-dry mass of an individual leaf divided by its water-saturated fresh mass). Both traits are variable and sensitive to variations in nutrient and water supply (LDMC and SLA) and light conditions 
(SLA), constituting main factors of adjustment in whole-plant response. Hence, variation in resource availability drives leaf traits in a way that is generally reflected in establishment of individuals with acquisitive traits (high SLA and low LDMC) in nutrient rich environments and conservative traits (low SLA and high LDMC) in nutrient poor environments (Wilson et al., 1999; Wright et al., 2004).

We harvested leaves from ten individuals per species $(\mathrm{dbh}>10 \mathrm{~cm})$ in each plot in the boreal and Mediterranean forests, and from at least six (monocultures) and three (mixed forest) trees in the temperate forest, due to the canopy height and difficulty sampling. We selected randomly the surveyed trees to maximise trait variability within species. We cut two branches at the most contrasting crown positions from each of the target trees, one located at the top and facing south, and the other at the bottom of the crown and facing north, and we collected five leaves/needles in each branch. Final sample size totalled 13,990 leaves from 1,403 trees (Appendix A, Table A.2). Leaf collection, storage, processing and trait measurement followed Garnier et al. (2001) and Pérez-Harguindeguy et al. (2013). We weighed rehydrated leaves, scanned them and measured their area using WinFOLIA and WinSEEDLE for broadleaves and needles, respectively (Regent Instruments Inc. Canada). Finally, they were oven-dried at $60^{\circ} \mathrm{C}$ for 72 hours and weighed for dry mass.

At the whole-plant level, we considered two traits from every single tree within the study plots $(5,036$ adult trees in total), namely tree height $(\mathrm{H})$ and crown projection area (CP). We calculated crown projection area assuming elliptical areas, using the projection of two perpendicular diameters (the longest one and its perpendicular) of the crown. Height and crown size can be considered individual performance measures (Garnier et al., 2016); but both variables represent the standing phenotypic variation in a tree community and the relative competitive ability of each individual for coexistence (Siefer et al., 2015). Moreover, our experimental design imply negligible ontogenetic differences at the plot level among 
individuals because our study sites comprised mature forests at late- to mid-stem exclusion stages with scattered individuals belonging to immature cohorts (Baeten et al., 2013). A summary of sample sizes per trait, species and forest type is shown in Table A.2 (Appendix A in Supporting Information).

\section{Statistical analyses}

Relative extent of intra- and interspecific trait variability on total community variability

We followed the approach developed by de Bello et al. (2011) to evaluate the relative contribution of ITV and ETV on total trait variability in every plot. This approach is based on the partitioning of total community (plot) trait variance into within- (ITV) and amongspecies (ETV) components, which is equivalent to the decomposition of the dissimilarity between pairs of observations, i.e. the quadratic entropy diversity (Rao index of functional diversity). Hence, the relative contribution of ITV in community $i$ (ITV rel, Eq. 1) is the ratio of the variance within species $j\left(\mathrm{ITV}_{\mathrm{abs}}\right.$ ) over the total community variance, which is the sum of abundance-weighted ITV and ETV. Similarly the relative contribution of ETV rel in community $i$ is the ratio of the variance among the species $j$ (ETV abs) over the total community variance (Eq. 2),

$$
\operatorname{ITVrel}_{i}=\frac{I T V a b s}{I T V a b s+E T V a b s}=\sum_{j}^{N s p} \frac{p_{i j} \frac{1}{\operatorname{Nind}_{i j}} \sum_{k}^{N i n d}\left(T_{i j k}-T_{i j}\right)^{2}}{\sum_{j}^{N s p} p_{i j} \frac{1}{\operatorname{Nind}_{i j}} \sum_{k}^{N i n d}\left(T_{i j k}-T_{i j}\right)^{2}+\sum_{j}^{N s p} p_{i j}\left(T_{i j}-T_{i}\right)^{2}} \text { (Eq. 1), }
$$

$$
\text { ETVrel }_{i}=\frac{\text { ETVabs }}{I T V a b s+E T V a b s}=\frac{\sum_{j}^{N s p} p_{i j}\left(T_{i j}-T_{i}\right)^{2}}{\sum_{j}^{N s p} p_{i j} \frac{1}{N i n d_{i j}} \sum_{k}^{N i n d}\left(T_{i j k}-T_{i j}\right)^{2}+\sum_{j}^{N s p} p_{i j}\left(T_{i j}-T_{i}\right)^{2}}
$$


where $N s p$ is the number of $j$ species and Nind the number of $k$ individuals sampled in a community (plot) $i, p_{i j}$ is the relative abundance of species $j$ in community $i, T_{i j k}$ is the trait value of the individual $k$ of the species $j$ in community $i, T_{i j}$ the mean trait value of the species $j$ in community $i$, and $T_{i}$ the mean trait value in community $i$. We used the relative species basal area in a plot (i.e. ratio of the sum of cross-sectional area of stems at breast height of each species over the sum of all species present in a plot) as the relative abundance. For foliar traits, we used SLA and LDMC per tree as the average of the ten harvested leaves. We chose the mean value among the most dissimilar leaves in each tree (collected from the two most light-contrasting locations in the crown) instead of leaves exposed to full sunlight, frequently used (Pérez-Harguindeguy et al., 2013), to have a fairer comparison across individuals as our sample included non-dominant individuals with no sun-exposed leaves. Note that ITV or ETV is used for intraspecific and interspecific trait variability in general terms, ITV $\mathrm{abs}_{\mathrm{ans}}$ and $\mathrm{ETV}_{\mathrm{abs}}$ for the absolute value of variability (variance expressed as squared units) assessed for each component, and ITV rel and ETV rel for the relative contribution (\%) of each component to the total variability at the community level.

We also evaluated the trait overlap at plot level using the $R$ function 'trova' (de Bello et al., 2013). It assesses the overlapping area between two trait distribution curves with kernel density estimators, not assuming any particular shape of the trait distribution (Mouillot et al., 2005).

\section{Relationship between intraspecific trait variability and species richness}

We checked the relationship between species richness (SR) and the ITV assessed at the community (plot) level (ITV abs) (Eq. 3). Then, we scaled down to the species level and analysed the relationship between species richness (SR) and trait mean $(\mathrm{T})$ of conspecific individuals (Eq. 4), and between species richness (SR) and trait variance at plot level per 
species, assessed as the coefficient of variation $(\mathrm{CV})(100 \times($ standard deviation / mean $))$ (Eq. 5). We fitted linear mixed models (LMMs) for the different response variables, which were log-transformed, as appropriate, to meet the assumptions of inferential statistics (normally distributed errors).

$$
\begin{gathered}
I T V_{a b s} \sim T F^{*} S R+(1 \mid \text { combination })+\varepsilon \\
T \sim S p * S R+\text { HCanopy }+T D+B A+B \text { Acon }+(1 \mid \text { combination } / \text { plot })+\varepsilon \\
C V \sim S p * S R+T D+B A+B \text { Acon }+(1 \mid \text { combination })+\varepsilon
\end{gathered}
$$

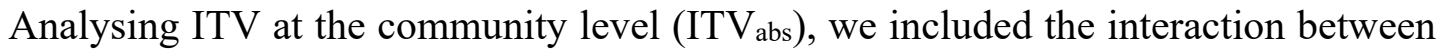
type of forest (TF) and species richness (SR) for analyses as fixed effect, allowing different responses to species richness among forest types. Analysing species trait responses, we included the interaction between species identity ( $\mathrm{Sp}$ ) and species richness, allowing different species responses for analyses at the species level. We ran models for each forest type separately, avoiding triple interactions and complex outcome interpretations. In addition, we included four covariates that describe the structure of the stand and account for any within-region variability due to historical management: i) tree density or number of adult trees in the plot (TD); i) plot basal area (BA), i.e. the sum of the basal area of all trees within a plot $\left(\mathrm{m}^{2}\right)$; iii) proportion of basal area considering only conspecific individuals (BAcon); and iv) the hierarchical position of each tree in the canopy (HCanopy) with a visual estimation into: 1) predominant; 2) dominant, 3) co-dominant; 4) dominated; 5) completely suppressed (Kraft, 1884). The latter was not considered when tree height was analysed, as they were highly correlated. Regarding the random structure, combination (i.e. species present in a plot) accounted for the variance among observations derived from specific species interactions in a community (see detailed species combinations in Table A.1, Appendix A), and plot for the expected correlation among trait observations within plots. 
We assessed the significance for each fixed effect by stepwise backward model selection, in which models of increasing complexity were compared to simpler ones using likelihood ratio (L-ratio) tests (Zuur et al., 2009), and we selected our optimal models following the principle of parsimony. For the analyses at the species level, we always retained the species identity and species richness (Sp and SR) in the models, to derive effect sizes for all models, but we removed non-significant covariates. Model parameters were estimated using a Restricted Maximum Likelihood approach, while Maximum Likelihood estimates were used when comparing models with L-ratio tests. LMMs were performed using the package 'Ime4' (Bates et al., 2014) in $R$ (R Core Team, version 3.3.1, 2016).

To compare the sole effect of species richness on study traits, we used the mean predicted values from the optimal LMMs of each trait at both extremes of the species richness gradient to assess the $d$ effect size (Cohen, 1988), i.e. the mean difference standardised by the pooled standard deviation of the two groups. We combined firstly the effect sizes by forest type, and secondly we pooled all to provide the grand mean effect size using fixed-effect models (Hedges and Vevea, 1998). We represented these effect sizes using the package 'metafor' in $R$ (Viechtbauer, 2010).

\section{RESULTS}

\section{Relative extent of intraspecific variability at the community level}

Comparing the relative extent of intra- vs. interspecific trait variability (ITV $\mathrm{V}_{\text {rel }}$ vs. ETV $V_{\text {rel }}$ ) showed that the contribution of ITV $V_{\text {rel }}$ was substantial in the three studied forests (Fig. 2), although the magnitude depended on the trait. Specifically, architectural trait variability (tree height and crown projection area) remained mainly within species (i.e. ITV rel 
was always over $50 \%$ ); while for leaf traits, the contribution of ITV $\mathrm{V}_{\text {rel }}$ was smaller, especially for SLA with contributions below $50 \%$.
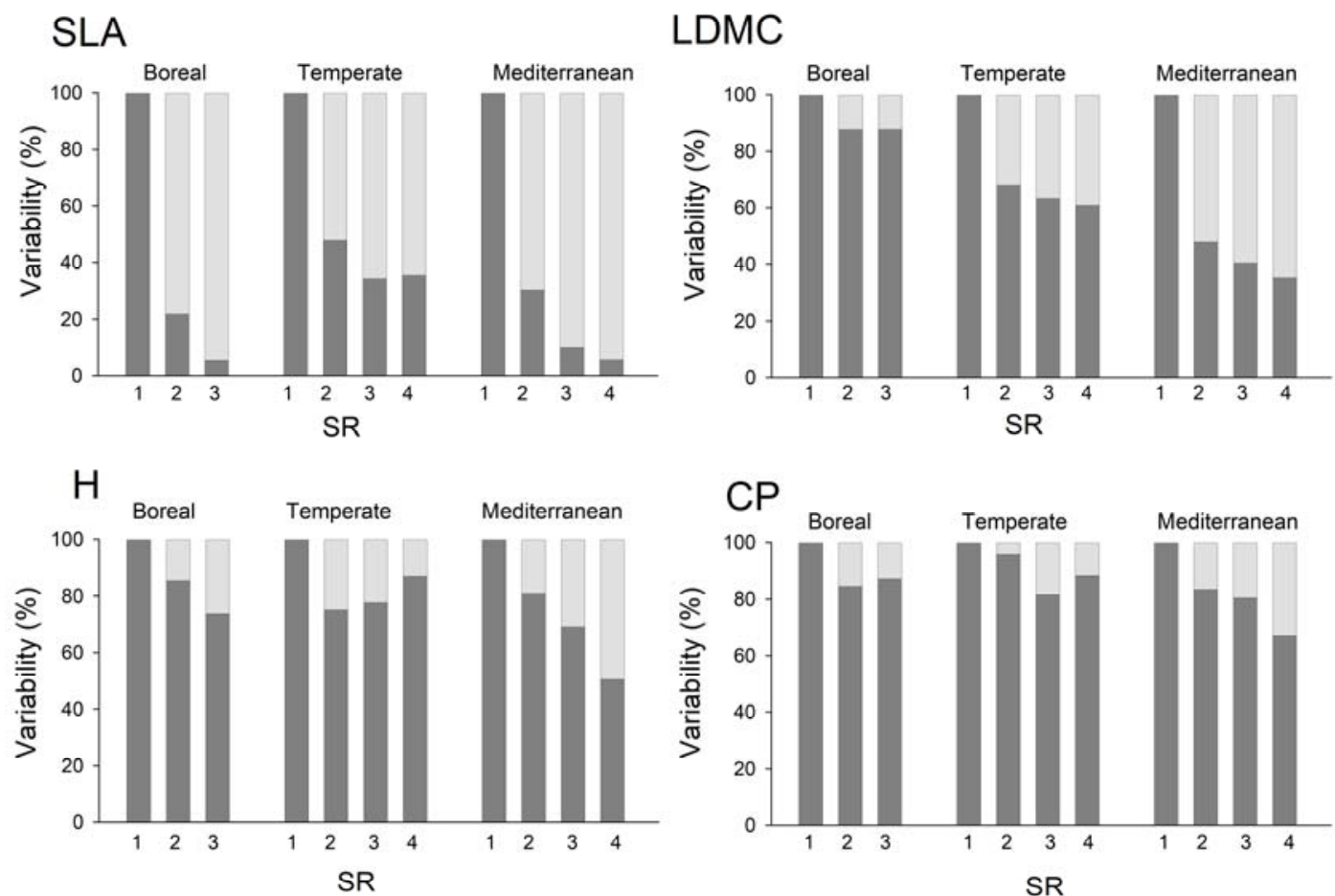

Fig. 2. Mean relative contribution of intraspecific (dark grey) and interspecific (light grey) variability to the community-level functional trait variability (in \%) assessed for the study traits (SLA: specific leaf area; LDMC: leaf dry matter content; $\mathrm{H}$ : tree height; CP: crown projection area). Each bar represents the average of communities (plots) with the same species richness level (SR) within each forest type.

Regarding patterns along the species richness gradient, we found some expected trends. All the variability found in monocultures was due to ITV by definition. Gradually, as the species richness increased, the variability at the community level (absolute values) increased, due to increments in both, inter- and intraspecific components (Fig. 3; Appendix B, Fig. B.1).These results are in accordance with Kumordzi et al. (2015) (see their Supporting Information) who evidenced a mathematical correlation between species richness and both components of the community trait variance. However, we found that the 
relative importance of ITV $\mathrm{rel}_{\text {rel }}$ decreased with species richness for both leaf traits, while the relationship depended on the forest type for architectural traits (Fig. 2). Finally, we also studied the relationship between SR and the species overlap for the four study traits, obtaining no significant effect (see Supporting Information, Fig. C.1).
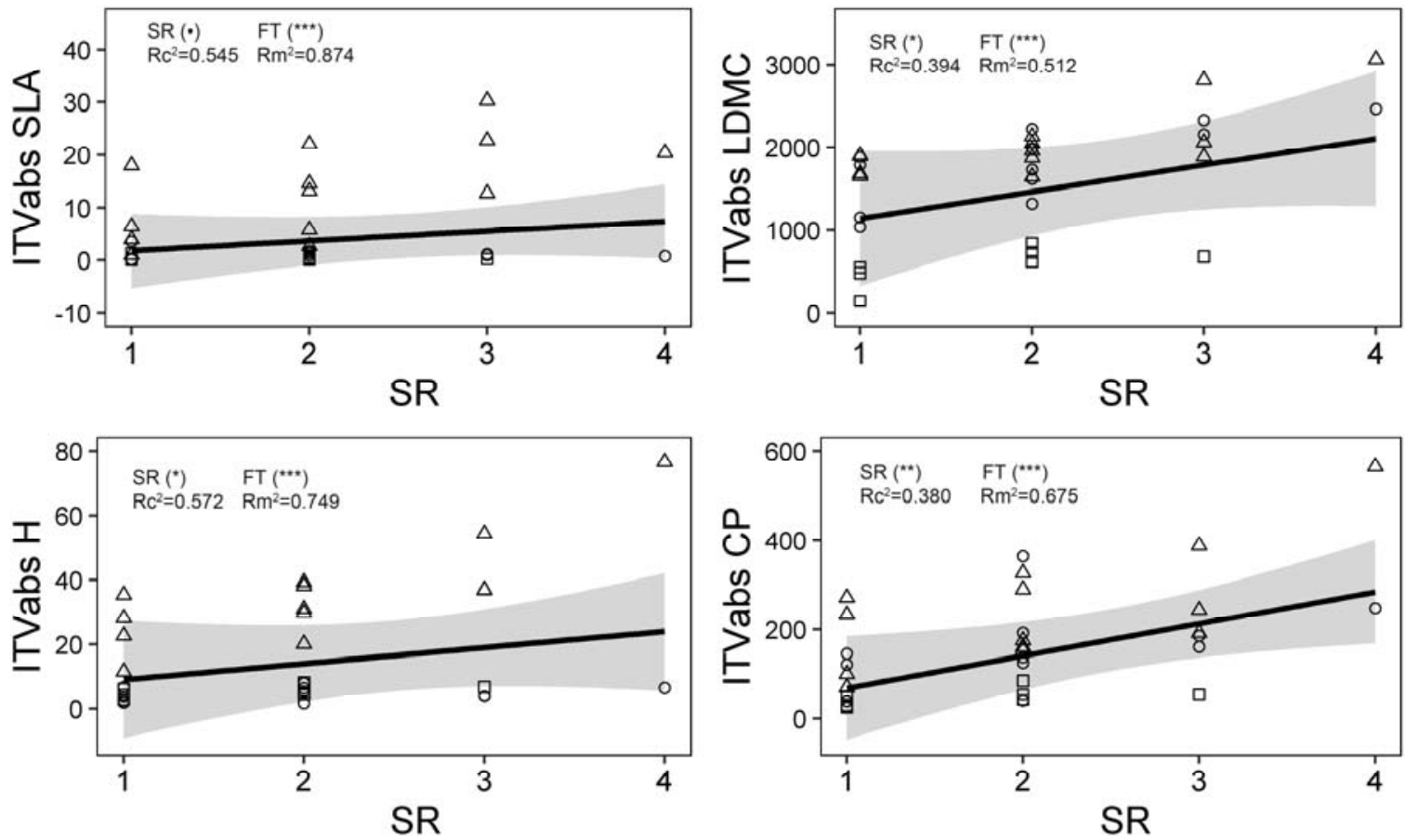

Fig. 3. Relationship between predicted ITV at community level (ITV abs) for the four study traits (SLA: specific leaf area; LDMC: leaf dry matter content; H: tree height; CP: crown projection area) and species richness (SR) with 95\% confidence intervals for fixed effects. $\mathrm{R}^{2}$ marginal and conditional of the models are shown, and significant SR and/or forest type $(\mathrm{FT})$ effects are indicated $(\bullet \mathrm{p}$-value $\leq 0.1, * \mathrm{p}$-value $\leq 0.05 ; * * \mathrm{p}$-value $\leq 0.01 ; * * * \mathrm{p}$-value $\leq 0.001)$. Squares are predicted values for the boreal forest, triangles for the temperate forest, and circles for the Mediterranean forest.

\section{Species trait patterns in relation to species richness}

Focusing on species-specific responses, we analysed the relationship between species richness (SR) and both mean trait values of conspecific individuals and trait variability at 
community (plot) level. The analyses showed divergent trends for leaf traits among forest types, and similar for architectural ones (Fig. 4; Table 2).

In the temperate forest, we found a clear positive relationship between species richness and SLA, and a negative relationship with LDMC. In the Mediterranean forest, species richness was positively correlated with LDMC, while in the boreal forest no significant pattern was found (Fig. 4a; Table 2; SI Appendix B Fig. B.2). Regarding the architectural traits, values of tree height and crown area did not show clear relationships with species richness, with species-specific responses (significant interaction between species richness and species) in the boreal and Mediterranean forests. However, trees were taller as the proportion of conspecific individuals (in basal area) increased, and as tree density decreased in the three study cases (Table 2; Fig. B.2). Moreover, trees generally had larger crown in less dense communities (Table 2).

The relationship between species richness and species trait variability at plot level (CV) was clearer in architectural than in leaf traits (Table 2). Despite the lower sample size, which implied wider confidence intervals (Fig. 4b), conspecific individuals in richer communities were more variable than in monocultures, at least in the boreal and temperate forests; while it was species-specific in the Mediterranean forest (Fig. 4b; Table 2; Fig. B.2). 
Table 2. Optimal linear mixed models for individual trait values and trait variability at plot level (CV, coefficient of variations) as response variables. The columns show the $\chi 2$ values from likelihood-ratio tests and the direction of each explanatory term selected.

\begin{tabular}{|c|c|c|c|c|c|c|c|c|c|c|c|c|}
\hline & & $\mathrm{Sp}$ & SR & $\mathrm{Sp} * \mathrm{SR}$ & Hcanopy & $\mathrm{TD}$ & BA & BAcon & $\mathrm{n}$ & $\triangle \mathrm{AIC}$ & marginal & itional \\
\hline \multirow{4}{*}{$\begin{array}{l}\overline{\mathscr{J}} \\
\ddot{0} \\
0\end{array}$} & SLA & $1514.14 * * *$ & 0.34 & & $(+) 37.23 * * *$ & & & & 460 & 5.73 & 0.972 & 0.978 \\
\hline & LDMC & $243.05 * * *$ & 0.49 & & $(-) 8.3 * *$ & & & $(-) 3.44 \cdot$ & 460 & 5.7 & 0.485 & 0.638 \\
\hline & $\mathrm{H}$ & $233.57 * * *$ & 0.63 & $32.32 * * *$ & & (-) $17.24 * * *$ & & $(+) 23.42 * * *$ & 1824 & 1.8 & 0.407 & 0.564 \\
\hline & $\mathrm{CP}$ & $16.57 * * *$ & 0.51 & & (-) $874.41^{* * *}$ & (-) $12.25 * * *$ & & $(-) 8.63 * * *$ & 1824 & 1.4 & 0.646 & 0.574 \\
\hline \multirow{4}{*}{ 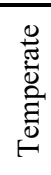 } & SLA & $484.95^{* *}$ & $5.24 *$ & & $(+) 45.96^{* * *}$ & & & & 226 & 2.97 & 0.921 & 0.929 \\
\hline & LDMC & $154.3^{* * *}$ & $7.65^{* *}$ & & & & & & 224 & 6.65 & 0.537 & 0.571 \\
\hline & $\mathrm{H}$ & $59.79 * * *$ & 0.17 & & & (-) $20.27 * * *$ & $(+) 9.34 * *$ & (+) $16.37 * * *$ & 1227 & 2.9 & 0.199 & 0.335 \\
\hline & $\mathrm{CP}$ & $118.45^{* * *}$ & 0.04 & & (-) $672.34 * * *$ & $(-) 3.81 \bullet$ & & & 1205 & 7.7 & 0.433 & 0.551 \\
\hline \multirow{4}{*}{ 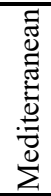 } & SLA & $1901.6^{* * *}$ & 0.55 & $10.48^{*}$ & $(+) 33.58 * * *$ & & & $(+) 2.78 \cdot$ & 700 & 3.76 & 0.947 & 0.959 \\
\hline & LDMC & $682.08^{* * *}$ & $4.78^{*}$ & & & & & & 686 & 10.5 & 0.644 & 0.729 \\
\hline & $\mathrm{H}$ & $293.35 * * *$ & $3.10^{\bullet}$ & $28.07 * * *$ & & (-) $6.71 * *$ & (+) $24.18^{* * *}$ & (+) $28.57 * * *$ & 1951 & 0 & 0.522 & 0.679 \\
\hline & $\mathrm{CP}$ & $107.81^{* * *}$ & 0.63 & $10.79 *$ & $(-) 1084.22 * * *$ & (-) $11.21 * * *$ & & & 1944 & 9.2 & 0.421 & 0.665 \\
\hline \multirow{4}{*}{$\begin{array}{l}\bar{\Xi} \\
\stackrel{0}{0} \\
0\end{array}$} & CV SLA & $102.36^{* * *}$ & 0 & & $\mathrm{nc}$ & & & & 48 & 2.72 & 0.882 & 0.895 \\
\hline & CVLDMC & $110.24 * * *$ & $3.5 \bullet$ & 4.82 • & $\mathrm{nc}$ & & & (-) $4.28^{*}$ & 48 & 3.22 & 0.905 & 0.905 \\
\hline & $\mathrm{CV} \mathrm{H}$ & $47.14 * * *$ & 3.33 • & & $\mathrm{nc}$ & & & & 48 & 3.6 & 0.622 & 0.625 \\
\hline & $\mathrm{CV}$ CP & $6.82 * * *$ & $4.32 *$ & & $\mathrm{nc}$ & (-) $5.28^{*}$ & & & 48 & 5.9 & 0.236 & 0.311 \\
\hline \multirow{4}{*}{ 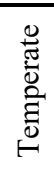 } & CV SLA & $16.44 * * *$ & 0.18 & & $\mathrm{nc}$ & & & & 61 & 7.55 & 0.218 & 0.304 \\
\hline & CV LDMC & $40.40^{* * *}$ & 2.32 & & $\mathrm{nc}$ & & & & 61 & 5.31 & 0.478 & 0.501 \\
\hline & $\mathrm{CV} \mathrm{H}$ & $19.39 * * *$ & $5.60^{*}$ & & $\mathrm{nc}$ & & & & 61 & 3.94 & 0.363 & 0.456 \\
\hline & $\mathrm{CV} \mathrm{CP}$ & $17.73 * * *$ & 1.36 & & $\mathrm{nc}$ & & & & 60 & 10.13 & 0.235 & 0.296 \\
\hline \multirow{4}{*}{ 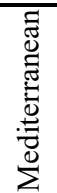 } & CV SLA & $64.44 * * *$ & 2.58 & $9.58^{*}$ & $\mathrm{nc}$ & $(+) 9.57^{* *}$ & & & 72 & 3.49 & 0.636 & 0.666 \\
\hline & CV LDMC & $75.46^{* * *}$ & 0.05 & & $\mathrm{nc}$ & & & & 71 & 2.71 & 0.639 & 0.728 \\
\hline & $\mathrm{CVH}$ & $10.93^{*}$ & 0.16 & & $\mathrm{nc}$ & & (-) $5.17^{*}$ & & 72 & 4.65 & 0.174 & 0.311 \\
\hline & $\mathrm{CV}$ CP & $23.91 * * *$ & 0.12 & $8.04 *$ & $\mathrm{nc}$ & $(-) 12.8 * * *$ & & & 72 & 3.52 & 0.378 & 0.58 \\
\hline
\end{tabular}

SLA: specific leaf area; LDMC: leaf dry matter content; H: tree height; CP: crown projection area; Sp: species; SR: species richness; HCanopy: hierarchical position in the canopy; TD: tree density in the plot; BA: basal area of the plot; Bacon: proportion of BA of conspecific individuals; $n$ : sample size; $\triangle \mathrm{AIC}$ : difference in AIC referred to the saturated model; nc: not considered in the saturated model. Significance: $\bullet 10 \%, * 5 \%, * * 1 \%, * * * 0.1 \%$. 
a) Traits at individual level

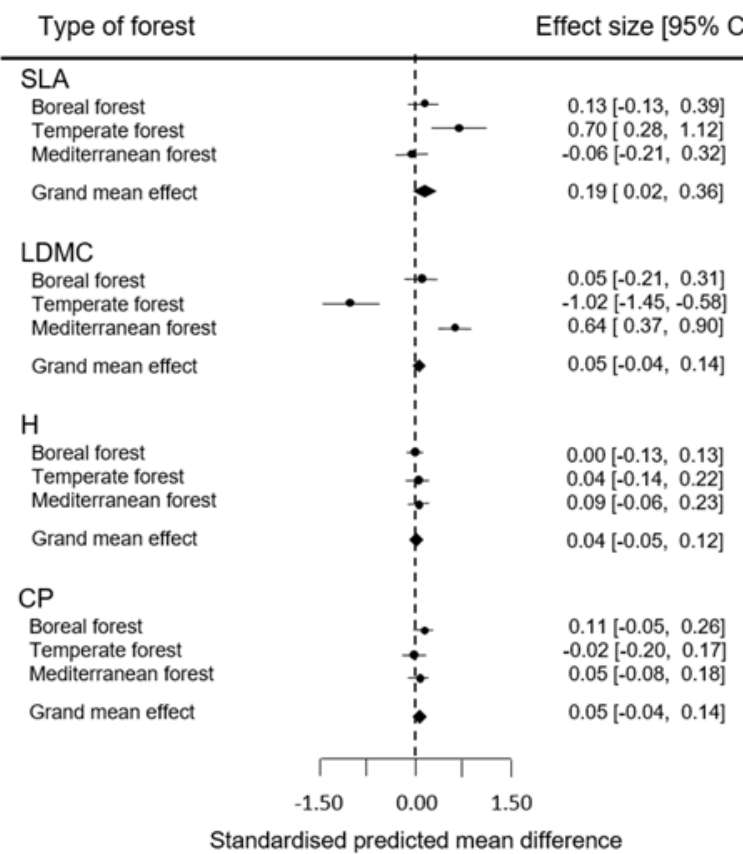

b) Traits at plot level (CV)

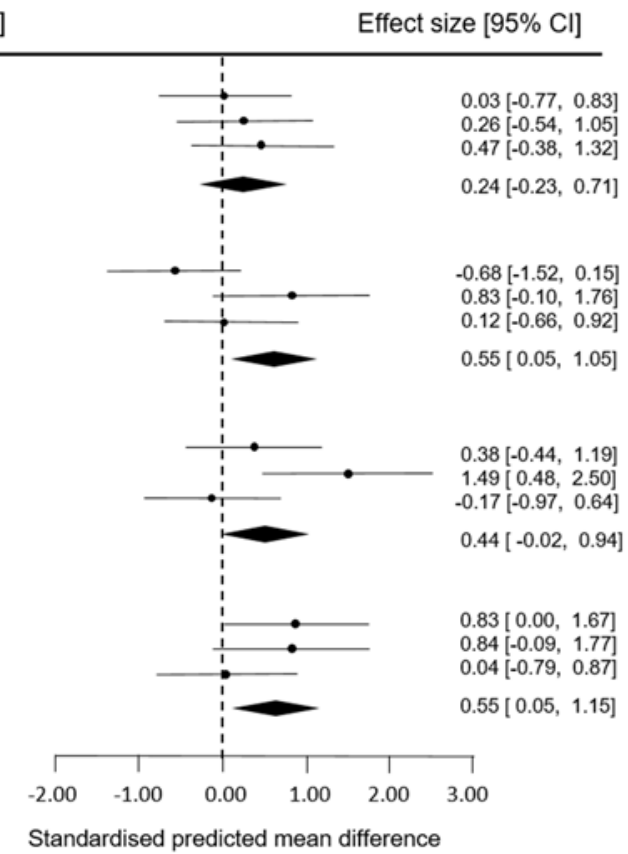

Fig. 4. Standardised effect sizes of species richness on: a) individual trait values; and b) trait variability at community (plot) level expressed as coefficient of variation -CVof the four study traits (SLA: specific leaf area; LDMC: leaf dry matter content; H: tree height; CP: crown projection area), using linear mixed models. Error bars represent $95 \%$ confidence intervals.

\section{DISCUSSION}

We explored two main questions regarding the relevance of intraspecific trait variability of tree species in European forests. First, we have observed an important contribution of ITV rel to the total variability at the community level for all the study traits, supporting the need for its incorporation in trait-based approaches to community ecology. Second, we have also found a slight adjustment of species traits in responses to the species richness of the neighbours that may promote species complementarity, although it varied among traits, species and forest types. Our results generally supported 
our third proposed hypothesis that trait variability increases in more diverse European forest communities, and that this increment is driven either by increased variability of conspecific individuals with more variable phenotypes or by shifts of mean trait values at a larger scale.

\section{Relative extent of intraspecific trait variability in European forests}

Trait variation within and among species may reach comparable magnitudes (Auger and Shipley, 2013; Fajardo and Piper, 2011), especially in species-poor communities where ITV contribution to community-level trait variability is expected to be larger than in highly diverse communities (Siefert et al., 2015). Our study forest communities, which are examples of the most representative and extensive types of European forests, are poor in terms of tree species richness compared to forest ecosystems in other regions. Our findings showed that ITV $\mathrm{V}_{\text {rel }}$ comprises a large amount of the community-level trait variability (often over 50\%), supporting our expectations. However, the magnitude depended on the trait considered, in agreement with previous studies (Auger and Shipley 2013; Siefert et al., 2015). Tree height and crown size variability mainly encompassed dissimilarities at the species level (higher ITV $\mathrm{V}_{\text {rel }}$ than ETV rel). This outcome is consistent with the fact that plants are modular organisms so whole-plant traits can accumulate more variability according to the local conditions where each module develops (Herrera 2009; Marks 2007; Siefert et al., 2015) than organ-level traits. Moreover, asymmetric competition for light enhances trait variability among individuals, regardless of the species, which accumulates throughout the lifespan of the plant.

Crucially, we found contrasting results for the two leaf traits. Variability in SLA was greater among species than within, and the opposite was true for LDMC. This 
finding can be explained by the fact that both traits are influenced by soil fertility and moisture but SLA is more influenced than LDMC by light conditions, which can vary enormously within a crown (Pérez-Harguindeguy et al., 2013; Wilson et al., 1999). Several studies have documented large variability in SLA within individuals conferring this variation on self-shading effects and complex interactions between soil fertility and light conditions (Reich et al., 2014; Wilson et al., 1999). However, in this study we omitted this component of the variability (within individuals), as we used averaged leaf traits per individual, and most of the remaining SLA variability was found between, instead of within, species. Contrasting variability patterns between these two traits are not new (Hulshof and Swenson, 2010; Roche et al., 2004) further supporting that the relative importance of ITV to ETV rely on the trait considered, species identity and communities.

\section{Relationship between species richness and species trait patterns}

We found that species richness correlated with ITV at the species level, although the strength and sign of the relationship depended on the study trait and forest type. Previous studies with grasslands also detected diversity-induced differences in species trait means (Gubsch et al., 2011; Roscher et al., 2015; Zuppinger-Dingley et al., 2014). Here, we found smaller conspecific individuals and with more variable architectures in richer communities (coefficient of variation of height and crown size at plot scale), which agrees with studies that report competition release, increased niche packing and a more efficient use of aboveground space in mixed stands compared to monocultures (Jucker et al., 2015; Pretzsch, 2014; Swenson and Weiser, 2014). In particular, Jucker et al. (2015), working in the same study sites, found greater vertical stratification and higher species crown variability in mixed stands compared to monocultures. 
Leaf trait means also correlated with species richness but the direction varied among forest types. In the temperate forest, individuals had higher SLA and lower LDMC in more diverse communities as typically shown in resource-rich environments (Wright et al., 2004). Increasing nutrient or water availability in soils of mixed vs. monospecific tree stands has often been postulated based on positive diversity effects on litter decomposition and nutrient cycling, and based on belowground resource use complementarity through niche partitioning and/or facilitation (Ashton et al., 2010; Richards et al., 2010; Rothe and Binkley, 2001). On the contrary, individuals in more diverse stands in the boreal and Mediterranean forests had leaves with higher LDMC than in monocultures, suggesting more stressful conditions for individuals in high diverse plots submitted to higher interspecific than intraspecific competition. Although we have no fitness measurements to confirm this assumption, previous studies in our boreal and Mediterranean study sites indicated that stressful conditions (e.g. droughts) boost competition for belowground resources in more diverse communities (Grossiord et al., 2014a, b; Jucker et al., 2014).

\section{Implications for biodiversity effect}

We have shown that plant individuals adjust some of their traits, and therefore the species functional space, to the biotic environment (see also Aschehoug and Callaway, 2010; Berg and Ellers, 2010; Callaway, 2003), namely to the richness of species. This is in agreement with results derived from biodiversity experiments (Gubsch et al., 2011; Liposky et al 2015; Mitchell and Bakker 2016; Roscher et al., 2015; Zuppinger-Dingley et al., 2014), which negates our first hypothesis (Fig.1). Moreover, we did not detect a pervasive shrinking of species trait breadths (variability at the community level) in mixed forests compared to monocultures, nor an increasing trait overlap with increasing 
species richness (see Appendix C, Fig. C.3), as would be predicted by the niche-based theory hypothesises - thus rejecting our second hypothesis- (Tilman 1982). On the contrary, our results support the third hypothesis, as we found some increments of trait variability and trait mean shifts as species richness increased. Moreover, we found that species overlaps remained steady at increasing richness suggesting both highly dissimilar or barely redundant species, as expected in poor-species communities (Valladares et al., 2015), and an expansion and packing of the functional space with increasing diversity in accordance to studies conducted in other forest communities (Pretzsch 2014; Swenson and Weiser, 2014).

Our results suggest that intraspecific trait variability, no matter the origin (either phenotypic plasticity or genetic diversity), provides species with the flexibility to avoid competition with coexisting species promoting complementarity instead (Aschehoug and Callaway, 2014; Ashton et al., 2010). Responses at the individual level to the presence of heterospecifics reduce functional similarity, favouring complementarity and resulting biodiversity effect on ecosystem functioning through two complementary ways. Firstly, shifts of leaf trait means along richness gradients would imply species short- and mid-term responses to canopy diversity, similar to the trait shifts found within herbaceous experiments (Gubsch, et al., 2011; Roscher et al., 2015). Secondly, assuming the modular nature of plants, these differential short-term responses among conspecifics would imply cumulative variation, resulting in more variable phenotypes (architectures) in the long-term (Herrera 2009). Furthermore, individuals with contrasting phenotypes create larger spatial heterogeneity, which in turn promotes associated biodiversity due to greater habitat availability (Stein et al., 2014). A limitation of our study is that we cannot fully remove the actual effect of historical management on these long-term responses, a common limitation when surveying long- 
lived organisms. However, results from biodiversity experiments in grasslands have reported similar cumulative phenotypic variability and species complementarity, augmenting the biodiversity effect through time (Reich et al., 2012; Tilman et al., 2006; Zuppinger-Dingley et al., 2014).

Collectively, our results demonstrate the relative importance of intraspecific trait variability to the functional diversity of plant communities highlighting its relevance for alleviation of competition and promotion of species complementarity.

\section{ACKNOWLEDGEMENTS}

We thank the entire 'leaf team' (for field support) and 'production team' (in charge of the measurements of tree heights and crown diameters) of the FunDivEUROPE project and especially to Rubén Freire, Annette Gockele, Marcel Böhrer, Lauren Smith and Jenna Mitchell for their incredible help in the field and laboratory. We are also grateful to Leena Finér, Margot Kaye and Olivier Bouriaud for the field organization support, and to Salvador Herrando-Pérez, Francesco de Bello, Ana Rey and Sophia Ratcliffe for their valuable comments and English editing.

All authors acknowledge support from the European Union FunDivEUROPE project (FP7-ENV-2010. Grant agreement No. 265171). RB was funded by a Marie Curie IEF fellowship (DIVEFOR. FP7-PEOPLE-2011-IEF. Grant Agreement No. 302445), together with the European Union's Horizon 2020 Research and Innovation Programme Project GenTree (Grant Agreement No. 676876), and REMEDINAL3-CM (Autonomous Community of Madrid, S2013/MAE-2719), LINCGlobal (4540-143AP), COMEDIAS (CGL2017-83170-R, Spanish Ministry of Science, Innovation and Universities) projects. 


\section{REFERENCES}

Albert, C.H., Thuiller, W., Yoccoz, N. G., Douzet, R., Aubert, S., Lavorel, S., 2010a. A multi-trait approach reveals the structure and the relative importance of intra- vs. interspecific variability in plant traits. Funct. Ecol. 24,1192-1201.

Albert, C. H., Thuiller, W., Yoccoz, N.G, Soudant, A., Boucher, F., Saccone, P., Lavorel, S., 2010b. Intraspecific functional variability: extent, structure and sources of variation. J. Ecol. 98, 604-613.

Allan, E. Weisser, W. Fischer, M., Schulze, E.D, Weigelt, A., Roscher, C., Baade, J., Barnard, R.L., Beßler, H., Buchmann, N., Ebeling, A., Eisenhauer, N., Engels, C., Fergus, A.J.F., Gleixner, G., Gubsch, M., Halle, S., Klein, A.M., Kertscher, I., Kuu, A., Lange, M., Le Roux, X., Meyer, S.T., Migunova, V.D., Milcu, A., Niklaus, P.A., Oelmann, Y., Pasălic, E., Petermann, J.S., Poly, F., Rottstock, T., Sabais, A.C.W., Scherber, C., Scherer-Lorenzen, M., Scheu, S., Steinbeiss, S., Schwichtenberg, G., Temperton, V., Tscharntke, T., Voigt, W., Wilcke, W., Wirth, C., Schmid, B., 2013. A comparison of the strength of biodiversity effects across multiple functions. Oecologia 173, 223-237.

Aschehoug, E.T., Callaway, R.M., 2014. Morphological variability in tree root architecture indirectly affects coexistence among competitors in the understory. Ecology 95, 1731-1736.

Ashton, I.W., Miller, A.E., Bowman, W.D., Suding, K.N., 2010. Niche complementarity due to plasticity in resource use: plant partitioning of chemical n forms. Ecology 91, $3252-3260$.

Auger, S., Shipley, B., 2013. Inter-specific and intra-specific trait variation along short environmental gradients in an old-growth temperate forest. J. Veg. Sci. 24, 419-428. 
Baeten, L., Verheyen, K., Wirth, C., Bruelheide, H., Bussotti, F., Finér, L., Jaroszewicz, B., Selvi, F., Valladares, F., Allan, E., Ampoorter, E., Auge, H., Avăcăriţei, D., Barbaro, L., Bărnoaiea, I., Bauhus, J., Beinhoff, C., Benavides, R., Benneter, A., Berger, S., Berthold, F., Boberg, J., Bonal, D., Brüggemann, W., Carnol, M., Castagneyrol, B., Charbonnier, Y., Chećko, E., Coomes, D., Coppi, A., Dalmaris, E., Dănilă, G., Dawud, S.M., de Vries, W., De Wandeler, H., Deconchat, M., Domisch, T., Duduman, G., Fischer, M., Fotelli, M., Gimeno, T.E., Granier, A., Grossiord, C., Guyot, V., Hantsch, L., Hattenschwiler, S., Hector, A., Hermy, M., Holland, V., Jactel, H., Koricheva, J., Lexer, M., Liebergesell, M., Müller, S., Muys, B., Nguyen, D., Nichiforel, L., Pollastrini, M., Radoglou, K., Raulund-Rasmussen, K., Seiferling, I., Stenlid, J., Vesterdal, L., von Wilpert, K., Zavala, M.A., Zielinski, D., SchererLorenzen M., 2013. A novel comparative research platform designed to determine the functional significance of tree species diversity in European forests. Perspect. Plant Ecol. Evol. Syst. 15, 281-291.

Balvanera, P., Pfisterer, A.B., Buchmann, He, J.S., Nakashizuka, T., Raffaelli, D., Schmid, B., 2006. Quantifying the evidence for biodiversity effects on ecosystem functioning and services. Ecol. Lett. 9, 1146-1156.

Bastias, C.C., Fortunel, C., Valladares, F., Baraloto, C., Benavides, R., Cornwell, W., Markesteijn, L., Oliveira, A.A., Sansevero, J.B.B., Vaz, M.C., Kraft, N.J.B. 2017. Intraspecific leaf trait variability along a boreal-to-tropical community diversity gradient. PLOS ONE, 12(2), e0172495.

Bates, D., Maechler, M., Bolker, B., Walker, S., Christensen, R.H.B., Singmann, H., Dai B., Grothendieck, G., Green, P., 2014. Package "Ime4". R Foundation for Statistical Computing, Vienna. 
Berg, M.P., Ellers, J., 2010. Trait plasticity in species interactions: a driving force of community dynamics. Evol. Ecol. 24, 617-629.

Cadotte, M.W., 2017. Functional traits explain ecosystem function through opposing mechanisms. Ecol. Lett. 20, 989-996.

Cadotte, M.W., Carscadden, K., Mirotchnick, N., 2011. Beyond species: functional diversity and the maintenance of ecological processes and services. J. Appl. Ecol. 48, $1079-1087$.

Callaway, R., 2003. Phenotypic plasticity and interactions among plants. Ecology 84, $1115-1128$.

Cardinale, B.J., Duffy, J.E., Gonzalez, A., Hooper, D.U., Perrings, C., Venail, P., Narwani, A., Mace, G.M., Tilman, D., Wardle, D.A., Kinzig, A.P., Daily, G.C., Loreau, M., Grace, J.B., Larigauderie, A., Srivastava, D.S., Naeem, S., 2012. Biodiversity loss and its impact on humanity. Nature 486, 59-67.

Carroll, I., Cardinale, B., Nisbet, R., 2011. Niche and fitness differences relate the maintenance of diversity to ecosystem function. Ecology 92, 1157-1165.

Cochrane, A., Yates, C.J., Hoyle, G.L., Nicotra, A.B., 2015. Will among-population variation in seed traits improve the chance of species persistence under climate change? Global Ecol. Biogeogr. 24, 12-24.

Cohen, J., 1988. Statistical power analysis for the behavioral sciences. Lawrence Earlbaum Associates. Hillsdale.

Crutsinger, M., Collins, M.D., Fordyce, J.A., 2006. Plant genotypic diversity predicts community structure and governs an ecosystem process. Science 313, 966-968.

de Bello, F., Carmona, C.P., Mason, N.W.H., Sebastià, M.T., Lep̌̌, J., 2013. Which trait dissimilarity for functional diversity: trait means or trait overlap? J. Veg. Sci. 24, 807-819. 
de Bello, F., Lavorel, S., Albert, C.H., Thuiller, W., Grigulis, K., Dolezal, J., Janeček, S., Lepš, J., 2011. Quantifying the relevance of intraspecific trait variability for functional diversity. Methods Ecol. Evol. 2, 163-174.

Ebeling, A. Pompe, S. Baade, J., Eisenhauer, N., Hillebrand, H., Proulx, R., Roscher, C., Schmid, B., Wirth, C., Weisser, W.W., 2014. A trait-based approach to understand the mechanisms underlying biodiversity-ecosystem functioning relationships. Basic Appl. Ecology 15, 229-240

Fajardo, A., Piper, F.I., 2011. Intraspecific trait variation and covariation in a widespread tree species (Nothofagus pumilio) in southern Chile. New Phytol. 189, 259-271.

Gamfeldt, L., Hillebrand, H., Jonsson, P.R., 2008. Multiple functions increase the importance of biodiversity for overall ecosystem functioning. Ecology 89, 12231231

Garnier, E., Laurent, G., Bellmann, A., Debain, S., Berthelier, P., Ducout, B., Roumet, C., Navas, M.-L., 2001. Consistency of species ranking based on functional leaf traits. New Phytol. 152, 69-83.

Garnier, E., Navas, M.L., Grigulis, K., 2016. Plant functional diversity: Organism traits community structure and ecosystem properties. Oxford University Press. Oxford.

Grossiord, C., Granier, A., Gessler, A., Jucker, T., Bonal, D., 2014a. Does drought influence the relationship between biodiversity and ecosystem functioning in boreal forests? Ecosystems 17, 394-404.

Grossiord, C., Granier, A., Ratcliffe, S., Bouriaud, O., Bruelheide, H., Checko, E., Forrester, D.I., Dawud, S.M., Finér, L., Pollastrini, M., Scherer-Lorenzen, M., Valladares, F., Bonal, D., Gessler, A. 2014b. Tree diversity does not always improve 
resistance of forest ecosystems to drought. Proc. Natl. Acad. Sci. USA 111, 1481214815.

Gubsch, M., Buchmann, N., Schmid, B., Schulze, E-D., Lipowsky, A., Roscher, C., 2011. Differential effects of plant diversity on functional trait variation of grass species. Ann. Bot-London 107, 157-169.

Hedges, L.V., Vevea, J.L., 1998. Fixed and random effects model in meta-analysis. Psychol. Methods 3, 486-501.

Herrera, C., 2009. Multiplicity in unity. Plant subindividual variation and interactions with animals. The University of Chicago Press. Chicago.

Hulshof, C.M., Swenson, N.G., 2010. Variation in leaf functional trait values within and across individuals and species: an example from a Costa Rican dry forest. Funct. Ecol. 24, 217-223.

Jucker, T., Bouriaud, O., Coomes, D.A., 2015. Crown plasticity enables trees to optimize canopy packing in mixed-species forests. Funct. Ecol. 29, 1078-1086.

Jucker, T., Bouriaud, O., Avăcăriţei, D., Dănilă, I., Duduman, G., Valladares, F., Coomes, D., 2014. Competition for light and water play contrasting roles in driving diversity-productivity relationships in Iberian forests. J. Ecol. 102, 1202-1213.

Jung, V., Violle, C., Mondy, C., Hoffmann, L., Muller, S., 2010. Intraspecific variability and trait-based community assembly. J. Ecol. 98, 1134-1140.

Kraft, G., 1884. Beiträge zur Lehre von den Durchforstungen Schlagstellungen und Lichtungshieben. Klindworth's Verlag Hannover.

Kraft, N.J.B., Godoy, O., Levine, J.M., 2015. Plant functional traits and the multidimensional nature of species coexistence. Proc. Natl. Acad. Sci. USA 112, 797-802. 
Kumordzi, B.B., de Bello, F., Freschet, G.T., Le Bagousse-Pinguet, Y., Lepš, J., Wardle D.A., 2015. Linkage of plant trait space to successional age and species richness in boreal forest understorey vegetation. J. Ecol. 103, 1610-1620.

Le Bagousse-Pinguet, Y., de Bello, F., Vandewalle, M., Leps, J., Sykes, M.T., 2014. Species richness of limestone grasslands increases with trait overlap: evidence from within- and between-species functional diversity partitioning. J. Ecol. 102, 466-474.

Lecerf, A., Chauvet, E., 2008. Intraspecific variability in leaf traits strongly affects alder leaf decomposition in a stream. Basic Appl. Ecol. 9, 598-605

Lefcheck, J.S., Byrnes, J.E.K., Isbell, F., Gamfeldt, L., Griffin, J.N., Eisenhauer, N., Hensel, M.J.S., Hector, A., Cardinale, B.J., Duffy, J.E., 2015. Biodiversity enhances ecosystem multifunctionality across trophic levels and habitats. Nature Commun. 6 . No. 6936.

Lichstein, J.W., Dushoff, J., Levin, S.A., Pacala, S.W., 2007. Intraspecific variation and species coexistence. Am. Nat. 170, 807-818.

Lipowsky, A., Roscher, C., Schumacher, J., Michalski, S. G., Gubsch, M., Buchmann, N., Schulze, E.-D., Schmid, B. 2015. Plasticity of functional traits of forb species in response to biodiversity. Perspect. Plant Ecol. Evol. Syst. 17, 66-77.

Loreau, M., Hector, A., 2001. Partitioning selection and complementarity in biodiversity experiments. Nature 412, 72-76.

Loreau, M., Sapijanskas, J., Isbell, F., Hector, A., 2012. Niche and fitness differences relate the maintenance of diversity to ecosystem function: comment. Ecology 93, $1482-1487$.

Marks, C.O., 2007. The causes of variation in tree seedling traits: the roles of environmental selection versus chance. Evolution 61, 455-469. 
McGill, B.J., Enquist, B.J., Weiher, E., Westoby, M. 2006. Rebuilding community ecology from functional traits. Trends Ecol. Evol. 21, 178-185.

Mitchell, R. M., J. D. Bakker. 2016. Grass abundance shapes trait distributions of forbs in an experimental grassland. J. Veg. Sci. 27:557-567.

Mouillot, D., Stubbs, W., Faure, M., Dumay, O., Tomasini, J.A., Wilson, J.B., Chi, T.D., 2005. Niche overlap estimates based on quantitative functional traits: a new family of non-parametric indices. Oecologia 145, 345-353.

Pérez-Harguindeguy, N., Díaz, S., Garnier, E., Lavorel, S., Poorter, H., Jaureguiberry, P., Bret-Harte, M.S., Cornwell, W.K., Craine, J.M., Gurvich, D.E., Urcelay, C., Veneklaas, E.J., Reich, P.B., Poorter, L., Wright, I.J., Ray, P,, Enrico, L., Pausas, J.G., de Vos, A.C., Buchmann, N., Funes, G., Quétier, F., Hodgson, J.G., Thompson, K., Morgan, H.D., ter Steege, H., van der Heijden, M.G.A., Sack, L., Blonder, B., Poschlod, P., Vaieretti, M.V., Conti, G., Staver, A.C., Aquino, S., Cornelissen, J.H.C., 2013. New handbook for standardised measurement of plant functional traits worldwide. Aust. J. Bot. 61, 167-234.

Pretzsch, H., 2014. Canopy space filling and tree crown morphology in mixed-species stands compared with monocultures. For. Ecol. Manag. 327, 251-264.

Reich, P.B., 2014. The world-wide "fast-slow" plant economics spectrum: a traits manifesto. J. Ecol. 102, 275-301.

Reich, P.B., Tilman, D., Isbell, F., Mueller, K, Hobbie, S.E., Flynn, D.F.B., Eisenhauer, N., 2012. Impacts of biodiversity loss escalate through time as redundancy fades. Science 336, 589-592

Richards, A.E., Forrester, D.I., Bauhus, J., Scherer-Lorenzen, M., 2010. The influence of mixed tree plantations on the nutrition of individual species: a review. Tree Physiol. 30, 1192-1208. 
Roche, P., Diaz-Burlinson, N., Gachet, S., 2004. Congruency analysis of species ranking based on leaf traits: which traits are the more reliable? Plant Ecol. 174, 37-48.

Roscher, C., Schumacher, J., Schmid, B., Schulze, E.D., 2015. Contrasting effects of intraspecific trait variation on trait-based niches and performance of legumes in plant mixtures. PLoSONE 10(3), e0119786.

Rothe, A., Binkley, D., 2001. Nutritional interactions in mixed species forests: a synthesis. Can. J. Forest Res. 31, 1855-1870.

Siefert, A., 2012. Incorporating intraspecific variation in tests of trait-based community assembly. Oecologia 170, 767-775.

Siefert, A., Violle, C., Chalmandrier, L., Albert, C.H., Taudiere, A., Fajardo, A., Aarssen, L.W., Baraloto, C., Carlucci, M.B., Cianciaruso, M.V., de L Dantas, V., de Bello, F., Duarte, L.D., Fonseca, C.R., Freschet, G.T., Gaucherand, S., Gross, N., Hikosaka, K., Jackson, B., Jung, V., Kamiyama, C., Katabuchi, M., Kembel, S.W., Kichenin, E., Kraft, N.J., Lagerström, A., Bagousse-Pinguet, Y.L., Li, Y., Mason, N., Messier, J., Nakashizuka, T., Overton, J.M., Peltzer, D.A., Pérez-Ramos, I.M., Pillar, V.D., Prentice, H.C., Richardson, S., Sasaki, T., Schamp, B.S., Schöb, C., Shipley, B., Sundqvist, M., Sykes, M.T., Vandewalle, M., Wardle, D.A., 2015. A global meta-analysis of the relative extent of intraspecific trait variation in plant communities. Ecol. Lett. 18, 1406-1419.

Stein, A., Gerstner, K., Kreft, H., 2014. Environmental heterogeneity as a universal driver of species richness across taxa, biomes and spatial scales. Ecol. Lett. 17, 866880.

Swenson, N.G., Weiser, M.D., 2014. On the packing and filling of functional space in eastern North American tree assemblages. Ecography 37, 1056-1062 
Tilman, D., 1982. Resource competition and community structure. Princeton University Press. Princeton.

Tilman, D., 2001. Functional diversity. In: Levin SA (ed) Encyclopaedia of Biodiversity. Academic Press, San Diego, pp 109-120.

Tilman, D., Reich, P.B., Knops, J.M.H., 2006. Biodiversity and ecosystem stability in a decade-long grassland experiment. Nature 441, 629-632.

Turnbull, L.A., Levine, J.M., Loreau, M., Hector, A., 2013. Coexistence, niches and biodiversity effects on ecosystem functioning. Ecol. Lett. 16, 116-127.

Valladares, F., Bastias, C.C., Godoy, O., Granda, E., Escudero, A., 2015. Species coexistence in a changing world. Front. Plant Sci. 6, 866.

Valladares, F., Matesanz, S., Araujo, M.B., Balaguer, L., Benito-Garzón, M., Cornwell, W., Gianoli, E., van Kleunen, M., Naya, D.E., Nicotra, A.B., Poorter, H., Zavala, M.A., 2014. The effects of phenotypic plasticity and local adaptation on forecasts of species range shifts under climate change. Ecol. Lett. 17, 1351-1364.

van der Plas, F., Manning, P., Allan, E., Scherer-Lorenzen, M., Verheyen, K., Wirth, C., Zavala, M.A., Hector, A., Ampoorter, E., Baeten, L., Barbaro, L., Bauhus, J., Benavides, R., Benneter, A., Berthold, F., Bonal, D., Bouriaud, O., Bruelheide, H., Bussotti, F., Carnol, M., Castagneyrol, B., Charbonnier, Y., Coomes, D., Coppi, A., Bastias, C.B., Dawud, S.M., De Wandeler, H., Domisch, T., Finer, L., Gessler, A., Granier, A., Grossiord, C., Guyot, V., Hättenschwiler, S., Jactel, H., Jaroszewicz, B., Joly, F.X., Jucker, T., Koricheva, J., Milligan, H., Müller, S., Muys, B., Nguyen, D., Pollastrini, M., Raulund-Rasmussen, K., Selvi, F., Stenlid, J., Valladares, F., Vesterdal, L., Zielínski, D., Fischer, M., 2016. Jack-of-all-trades' effects drive biodiversity-ecosystem multifunctionality relationships. Nature Commun. 7, No. 11109. 
Viechtbauer, W., 2010. Conducting meta-analyses in R with the metafor package. J. Stat. Soft. 36, 1-48.

Violle, C. Enquist, B.J. McGill, B.J. Jiang, L. Albert, C.H. Hulshof, C., Jung, V., Messier, J., 2012. The return of the variance: intraspecific variability in community ecology. Trends Ecol. Evol. 27, 244-252.

Wilson, P.J, Thompson, K., Hodgson, J.G., 1999. Specific leaf area and leaf dry matter content as alternative predictors of plant strategies. New Phytol. 143, 155-162.

Wright, I.J., Reich, P.B., Westoby, M., Ackerly, D.D., Baruch, Z., Bongers, F., Cavender-Bares, J., Chapin, T., Cornelissen, J.H., Diemer, M., Flexas, J., Garnier, E., Groom, P.K., Gulias, J., Hikosaka, K., Lamont, B.B., Lee, T., Lee, W., Lusk, C., Midgley, J.J., Navas, M.L., Niinemets, U., Oleksyn, J., Osada, N., Poorter, H., Poot, P., Prior, L., Pyankov, V.I., Roumet, C., Thomas, S.C., Tjoelker, M.G., Veneklaas, E.J., Villar, R., 2004. The worldwide leaf economics spectrum. Nature 428, 821-827.

Zhu, J. van der Werf, W. Anten, N.P.R. Vos, J. Evers, J.B., 2015. The contribution of phenotypic plasticity to complementary light capture in plant mixtures. New Phytol. 207, 1213-1222.

Zuppinger-Dingley, D. Schmid, B. Petermann, J.S., Yadav, V., De Deyn, G.B., Flynn, D.F.B., 2014. Selection for niche differentiation in plant communities increases biodiversity effect. Nature 515, 108-111.

Zuur, A.F. Ieno, E.N., Walker, N.J. Saveliev, A. A., Smith, G.M., 2009. Mixed Effects Models and Extensions in Ecology with R. Springer. New York. 


\section{Appendix A: Study sites and sampling design}

Table A.1. Plot design and species composition in each study site.

\begin{tabular}{|c|c|c|c|c|c|c|c|c|c|c|c|c|c|c|}
\hline & \multicolumn{4}{|c|}{ Boreal } & \multicolumn{5}{|c|}{ Temperate } & \multicolumn{5}{|c|}{ Mediterranean } \\
\hline & $B p$ & $P a$ & $P S$ & No. plots & $A a$ & $A p$ & $F s$ & $P a$ & No. plots & $P n$ & $P s$ & $Q i$ & $Q f$ & No. plots \\
\hline \multirow{4}{*}{ Monoculture } & $\mathrm{x}$ & & & 4 & $\mathrm{x}$ & & & & 2 & & & $x$ & & 3 \\
\hline & & $\mathrm{x}$ & & 4 & & $\mathrm{x}$ & & & 2 & & & & $\mathrm{x}$ & 3 \\
\hline & & & $\mathrm{x}$ & 4 & & & $\mathrm{x}$ & & 2 & & $\mathrm{x}$ & & & 3 \\
\hline & - & - & - & - & & & & $\mathrm{x}$ & 2 & $\mathrm{x}$ & & & & 3 \\
\hline \multirow{5}{*}{ 2-sp mixture } & $\mathrm{x}$ & $\mathrm{x}$ & & 4 & $\mathrm{x}$ & & & $\mathrm{x}$ & 2 & $\mathrm{x}$ & & & $\mathrm{x}$ & 3 \\
\hline & & $\mathrm{x}$ & $\mathrm{x}$ & 4 & & $\mathrm{x}$ & $\mathrm{x}$ & & 2 & $\mathrm{x}$ & $\mathrm{x}$ & & & 3 \\
\hline & $\mathrm{x}$ & & $\mathrm{x}$ & 4 & & & $\mathrm{x}$ & $\mathrm{x}$ & 2 & & $\mathrm{x}$ & & $\mathrm{x}$ & 3 \\
\hline & - & - & - & - & $\mathrm{x}$ & & $\mathrm{x}$ & & 3 & & & $\mathrm{x}$ & $\mathrm{x}$ & 3 \\
\hline & - & - & - & - & & $\mathrm{x}$ & & $\mathrm{x}$ & 1 & $\mathrm{x}$ & & $\mathrm{x}$ & & 3 \\
\hline \multirow{3}{*}{ 3-sp mixture } & $\mathrm{x}$ & $\mathrm{x}$ & $\mathrm{x}$ & 4 & $\mathrm{x}$ & $\mathrm{x}$ & $\mathrm{x}$ & & 2 & $\mathrm{x}$ & & $\mathrm{x}$ & $\mathrm{x}$ & 3 \\
\hline & - & - & - & - & $\mathrm{x}$ & & $\mathrm{x}$ & $\mathrm{x}$ & 3 & $\mathrm{x}$ & $\mathrm{x}$ & & $\mathrm{x}$ & 3 \\
\hline & - & - & - & - & & $\mathrm{x}$ & $\mathrm{x}$ & $\mathrm{x}$ & 2 & - & - & - & - & - \\
\hline 4-sp mixture & - & - & - & - & $\mathrm{x}$ & $\mathrm{x}$ & $\mathrm{x}$ & $\mathrm{x}$ & 3 & $\mathrm{x}$ & $\mathrm{x}$ & $\mathrm{x}$ & $\mathrm{x}$ & 3 \\
\hline Total & & & & 28 & & & & & 28 & & & & & 36 \\
\hline
\end{tabular}

Bp: Betula pendula; Pa: Picea abies; Ps: Pinus sylvestris; Aa: Abies alba; Ap: Acer pseudoplatanus; Fs: Fagus sylvativa; Pn: Pinus nigra; Qf: Quercus faginea; Qi: Quercus ilex. 
Table A.2. Sample size for each surveyed species.

\begin{tabular}{llcccc} 
Type of forest & Target species & No. plots & Trees $^{\dagger}$ & Sampled trees $^{\dagger}$ Sampled leaves \\
\hline Boreal & Betula pendula & 16 & 329 & 142 & 1420 \\
& Picea abies & 16 & 837 & 160 & 1600 \\
& Pinus sylvestris & 16 & 660 & 158 & 1580 \\
Temperate & Abies alba & 15 & 284 & 56 & 560 \\
& Acer pseudoplatanus & 12 & 241 & 41 & 410 \\
& Fagus sylvatica & 17 & 451 & 80 & 790 \\
\multirow{3}{*}{ Mediterranean } & Picea abies & 15 & 277 & 55 & 550 \\
& Pinus nigra & 21 & 504 & 210 & 2100 \\
& Pinus sylvestris & 15 & 377 & 144 & 1440 \\
& Quercus faginea & 21 & 740 & 208 & 2070 \\
& Quercus ilex & 15 & 336 & 149 & 1485 \\
\hline TOTAL & & 92 & 5036 & 1403 & 13990
\end{tabular}

'Tress' refers to the total number of standing individuals in the study plots, and therefore used for the assessment of whole-plant level traits (tree height and crown projection area); while 'Sampled trees' refers to those harvested for leaf traits' assessment (SLA and LDMC). 

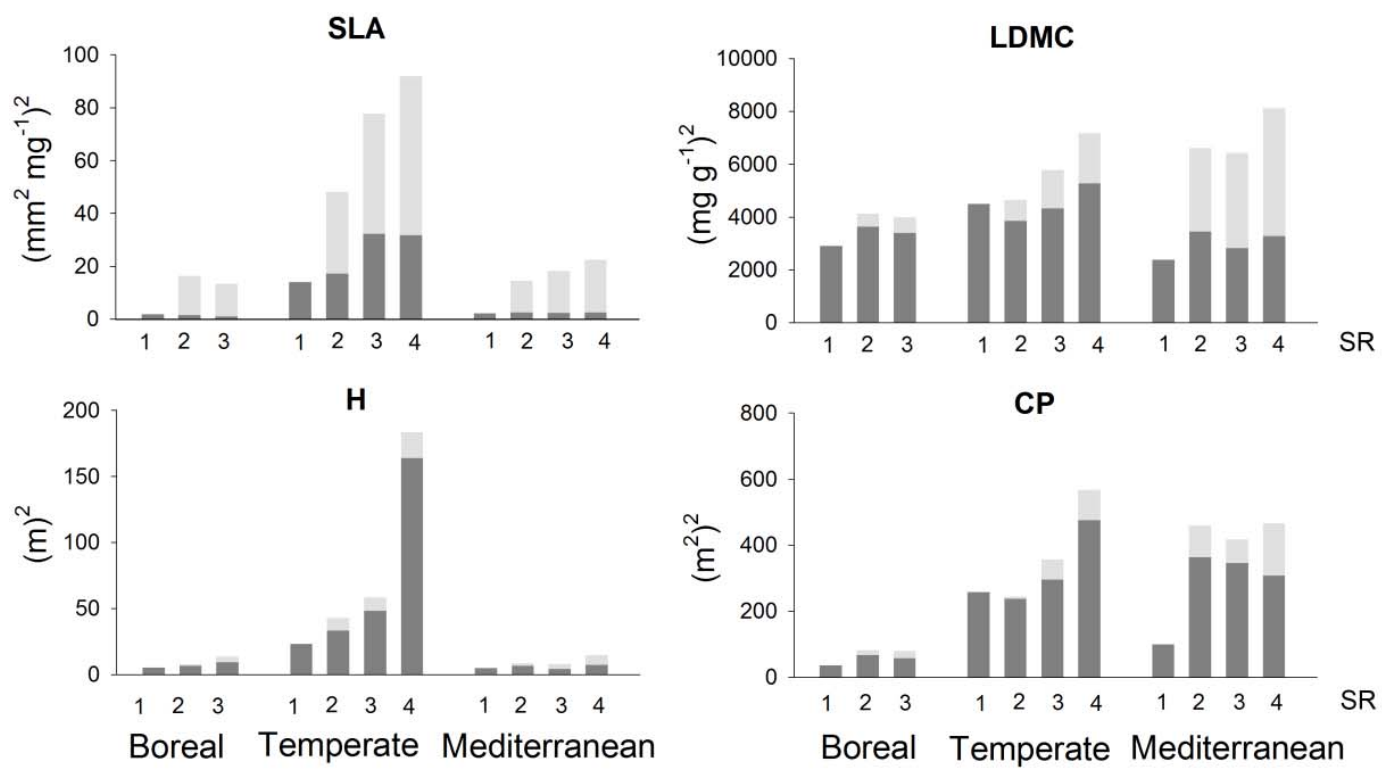

Fig. B.1 Absolute values of intraspecific trait variability assessed for each trait at plot level and averaged per species richness level and site. Dark grey shows the intraspecific component and light grey the interspecific component of the total variance. SLA: specific leaf area; LDMC: leaf dry matter content; H: tree height; CP: crown projection area. These values are expressed in terms of variance (squared units). 

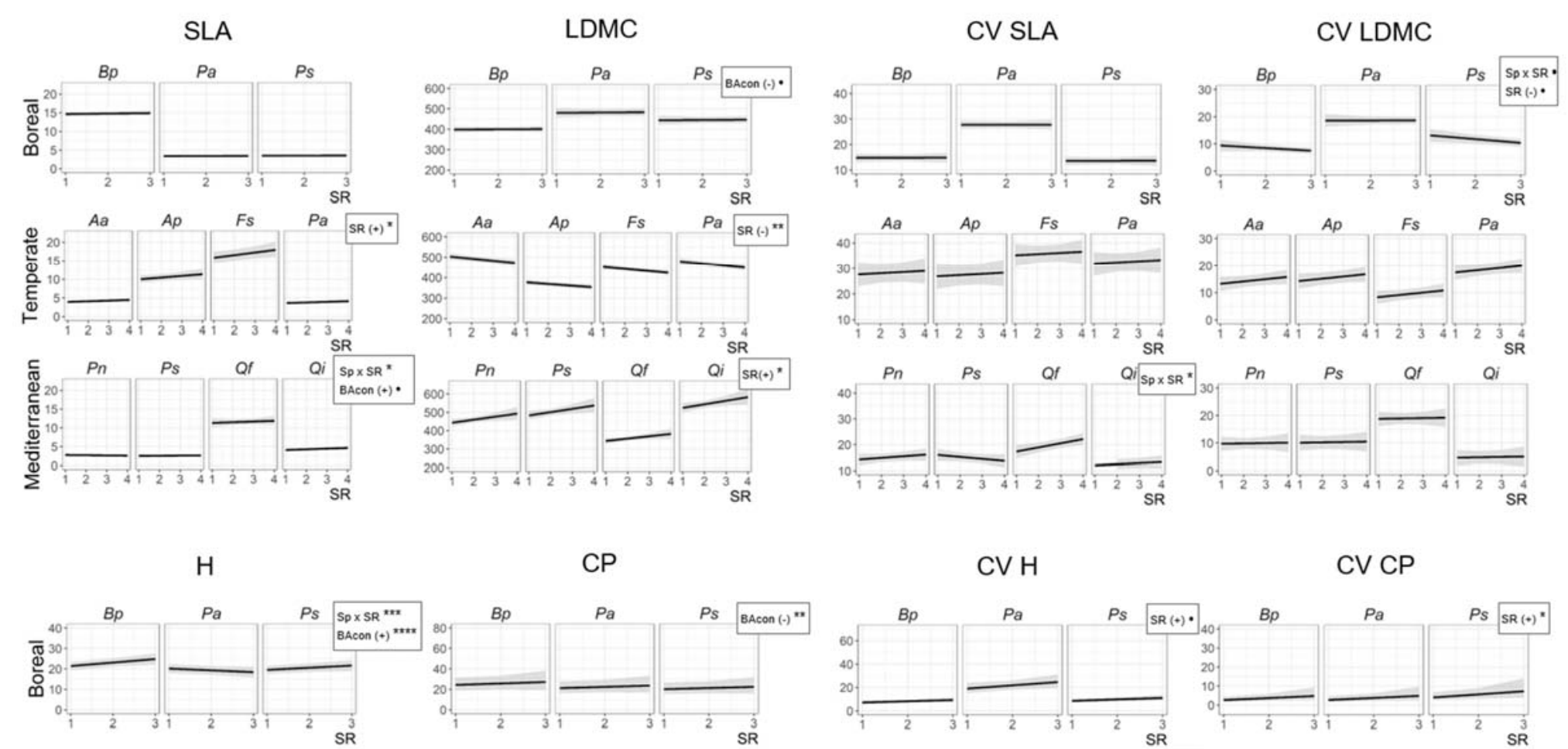

CV CP
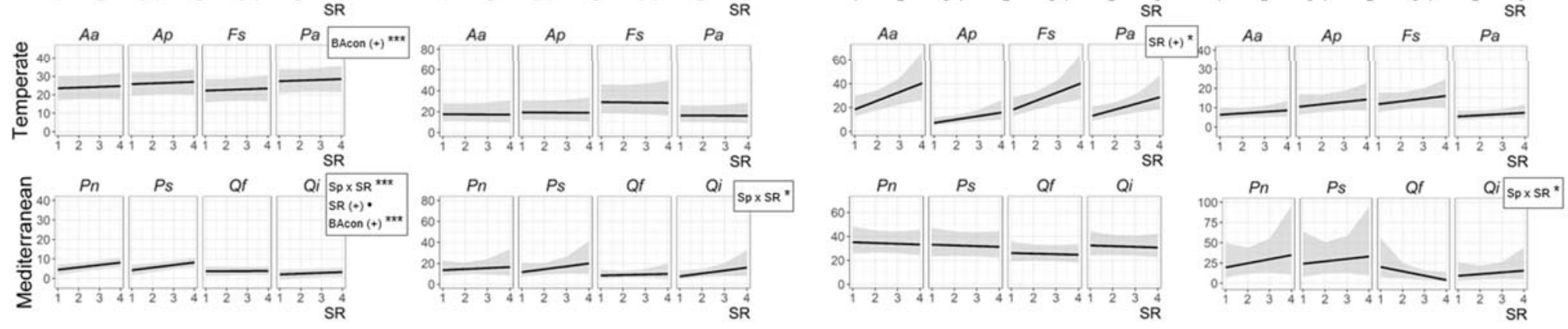

Fig. B.2. Predicted trait trends along the species richness gradient (SR), shown for each tree species within each forest type. Liner mixed models were run for individual trait values and coefficient of variation within a species at plot level (CV). Models with significant BAcon (basal area of conspecific individuals), SR effect and/or its interaction with species (Sp) are indicated, including the sign and significance level. The 95\% confidence intervals are shown assessed for the fixed effects. (SLA: specific leaf area; LDMC: leaf dry matter content; H: tree height; CP: crown projection area; Bp: Betula pendula; Pa: Picea abies; Ps: Pinus sylvestris; Aa: Abies alba; Ap: Acer pseudoplatanus; Fs: Fagus sylvativa; Pn: Pinus nigra; Qf: Quercus faginea; Qi: Quercus ilex; • p-value $\leq 0.1$, * p-value $\leq 0.05 ; * *$-value $\leq 0.01 ; * * *$-value $\leq 0.001)$. 
Appendix C: Species niche overlap
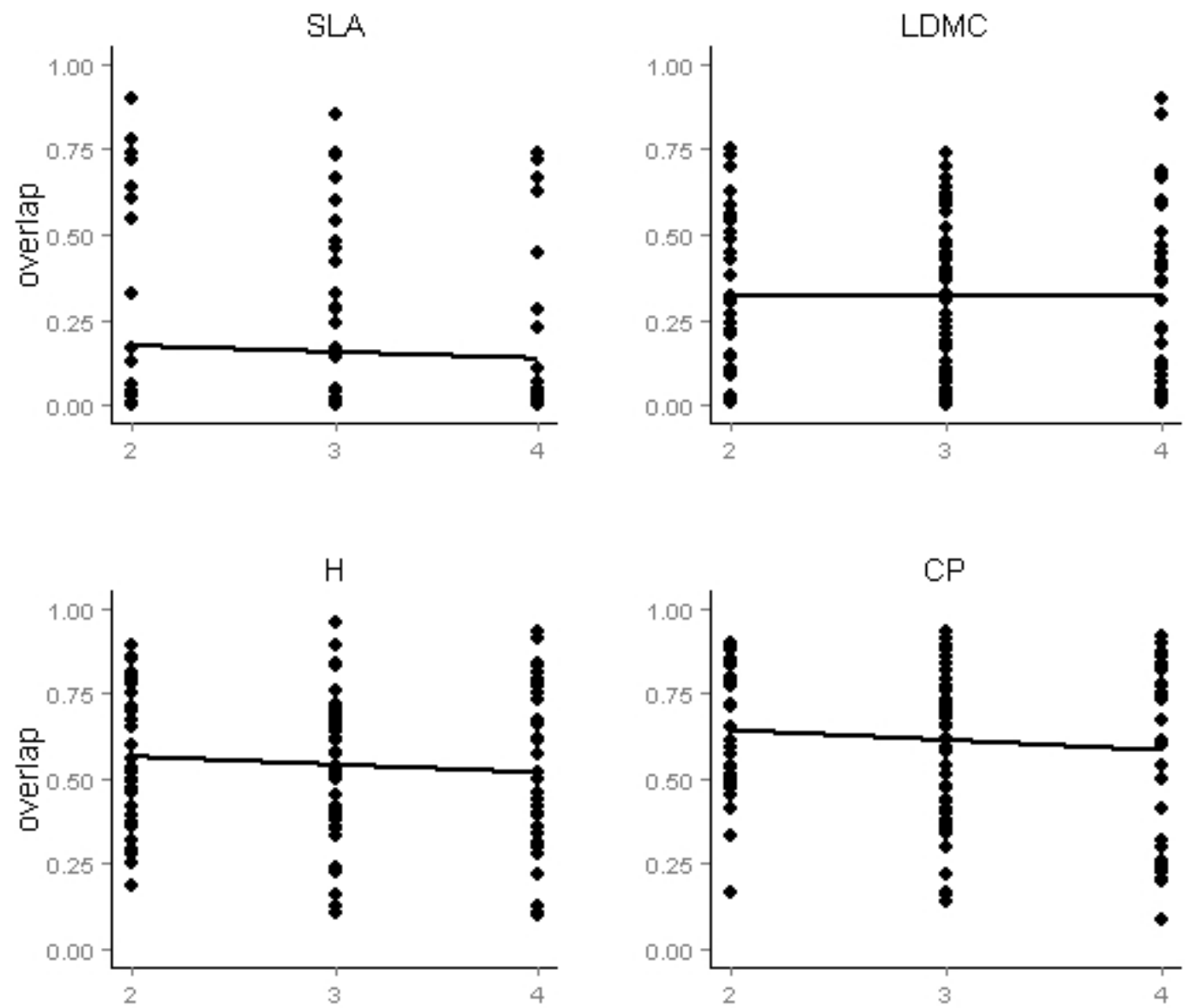

Species richness

Fig. C.1. Species niche overlaps considering the four study traits along the species richness gradient. SLA: specific leaf area; LDMC: leaf dry matter content; H: tree height; CP: crown projection area. 